\title{
A Major Event of Self-mutilation in a Patient with Fetal Alcohol Syndrome
}

\author{
Joel P. Johnson M.D. (PGY4) \\ University of California, Davis, joel.johnson@ucdmc.ucdavis.edu
}

Steven Sugden M.D.

University of California, Davis, stevesugden@surewest.net

James A. Bourgeois O.D., M.D.

University of California, Davis, james.bourgeois@ucdmc.ucdavis.edu

Follow this and additional works at: https://jdc.jefferson.edu/jeffjpsychiatry

Part of the Psychiatry Commons

Let us know how access to this document benefits you

\section{Recommended Citation}

Johnson, Joel P. M.D. (PGY4); Sugden, Steven M.D.; and Bourgeois, James A. O.D., M.D. (2007) "A Major Event of Self-mutilation in a Patient with Fetal Alcohol Syndrome," Jefferson Journal of Psychiatry. Vol. 21

: Iss. 1 , Article 3.

DOI: https://doi.org/10.29046/JJP.021.1.003

Available at: https://jdc.jefferson.edu/jeffjpsychiatry/vol21/iss $1 / 3$

This Article is brought to you for free and open access by the Jefferson Digital Commons. The Jefferson Digital Commons is a service of Thomas Jefferson University's Center for Teaching and Learning (CTL). The Commons is a showcase for Jefferson books and journals, peer-reviewed scholarly publications, unique historical collections from the University archives, and teaching tools. The Jefferson Digital Commons allows researchers and interested readers anywhere in the world to learn about and keep up to date with Jefferson scholarship. This article has been accepted for inclusion in Jefferson Journal of Psychiatry by an authorized administrator of the Jefferson Digital Commons. For more information, please contact: JeffersonDigitalCommons@jefferson.edu. 


\section{A Major Event of Self-mutilation in a Patient with Fetal Alcohol Syndrome}

Joel P. Johnson, M.D. (PGY4), Steven G. Sugden, M.D., James A. Bourgeois, O.D., M.D.

\section{ABSTRACT}

We describe a young adult male with fetal alcohol syndrome (FAS) who presented with a non-repetitive, major, genital self-mutilation necessitating urological intervention. On formal psychiatric evaluation, he did not have psychosis or suicidality. Most commonly, self-injury in developmental disability is less severe and more stereotypic; major-class self-mutilation is confined, generally, to psychosis. It is this discrepancy that is the unusual feature of our case.

\section{CASE REPORT}

A 22 year-old-male with fetal alcohol syndrome (FAS) presented to a local emergency department with fever, chills, anorexia, and dysuria. Temperature was $39.1 \mathrm{C}$, blood pressure $106 / 51 \mathrm{mmHg}$, heart rate 156 beats/min, and respirations $18 / \mathrm{min}$. White blood cell count was $13.1\left(10^{3} / \mu \mathrm{l}\right)$; serum chemistries were normal. A metal chain had been inserted by the patient into his urethra. No inguinal swelling, penile discharge, genital lesions, or testicular pain were noted. When the emergency-department physician was unable to remove the chain, the patient was transferred to the regional tertiary medical center for urological examination and intervention.

Abdominal film and pelvic CT-scan revealed a metal chain, lodged within the urethra, and a mass in the bladder. Cystoscopy was performed. The chain $(50 \mathrm{~cm} \mathrm{X} 0.5 \mathrm{~cm})$ was removed from the urethra, and a calcified toy frog $(1.5 \mathrm{~cm}$ X $2.0 \mathrm{~cm}$ X $2.5 \mathrm{~cm})$ was retrieved from the bladder (figure 1). There were no surgical complications. Ampicillin and gentamicin commenced, as well as oxybutynin and hydrocodone/acetaminophen. Blood cultures revealed no growth, but urine cultures showed growth of Escherichia coli. Ciprofloxacin replaced ampicillin and gentamicin. A head CT-scan revealed microcephaly with no advanced atrophy or focal lesions. 
The hospital's psychiatric consultation-liaison team was consulted. Microcephaly was present; the jaws were elongated. Prior neuropsychiatric assessments were obtained: intelligence quota (IQ) was below 70. The patient was oriented to location and city, but not to time. He could not remember the events pertinent to his hospitalization. He stated that he was not suicidal, not depressed, and not experiencing command hallucinations. Clinical impression was that of a unique, impulsive event in response to psychosocial stressors. Risperidone $0.5 \mathrm{mg}$ twice daily was started. After appetite improved and leukocytosis resolved, he was discharged home with outpatient psychiatric follow-up.

Historical information was gathered from family members and from further interview with the patient. Owing to neglect by the biological mother, he had been adopted at five months of age, and since that time had lived in the same house with the same adoptive parents. He was the fifth of six children. The youngest sister, who also had FAS, was adopted by the same family. Unlike the patient, the sister has a sustained habit of selfinjurious behavior, specifically head-banging. The patient had been diagnosed with attention-deficit/hyperactivity disorder, inattentive type; dexedrine has been prescribed since the age of 12 .

Both children reported verbal and physical abuse by their estranged, adoptive father. The type of physical abuse suffered by the patient was being slapped on the face. He reported fear of retribution by the father for reporting the physical abuse to his care-coordinator. Neither the patient nor his adoptive mother recalled or reported sexual abuse to three different interviewers, including interview with the patient's long-term carecoordinator. The patient and his mother did recall a single instance of homosexual play the patient and a peer engaged in at age eight.

The adoptive parents separated 7 months prior to the hospitalization, and no contact with the adoptive father had taken place since. After the separation, the patient destroyed various items given to him by the father. A month prior to the hospitalization, the patient contemplated suicide by cutting his wrists. He explained as follows, "I thought the drain [of blood] would make me die and that would hurt dad." After obtaining a pocketknife and locking himself in the bathroom, he became too frightened to follow through. Two weeks later both the patient and his sister were scheduled to attend summer camp, but the adoptive mother decided not to send the children because the sister became ill. In the two weeks that followed, the patient was more withdrawn and spent more time in bed than usual. It was

Jefferson Journal of Psychiatry, Volume 21, Number 1

(C) 2007 by the authors

On the Web: jdc.jefferson.edu/jeffjpsychiatry

ISSN 1935-0783 
then that he inserted the toy frog into his urethra: "I didn't hurt dad but I thought it would." His mother did not know of this act until the consequence of it was discovered at the hospital. No further history of previous suicide attempt or self-mutilation could be elicited, nor was there history of mania or psychosis.

After these interviews, the WAIS III was administered: verbal IQ 64; performance IQ 78; full-scale IQ 67. On the Aberrant Behavioral Checklist, there were social isolation, withdrawal, and irritability, but irritability did improve on risperidone $0.5 \mathrm{mg}$ twice daily. No more self-injurious behavior has been observed.

\section{DISCUSSION}

FAS has become accepted as a leading identifiable cause of mental retardation and neurologic deficit (1). Comorbid psychiatric illness is common: ADHD; anxiety and mood disorders; disruptive behavior and conduct disorder; intermittent explosive disorder; and complex learning disabilities (2). Burd et al. (3) reviewed the neuropsychiatric comorbidities of 152 children diagnosed with FAS: the prevalence of self-injurious behavior was $10.5 \%$ (relative risk 1.2). In the FAS spectrum, obvious contributors to the higher relative risk of self-injury are poor CNS development and a high likelihood of being raised in an adverse environment. In both human and non-human primates, aberrant stereotyped behavior, including self-injury, has been associated with adverse environmental circumstances and early CNS damage (4).

Currently, self-mutilation is classified as follows. The major class is characterized by infrequent acts of severe tissue damage, e.g., eyeenucleation, and is most often associated with psychosis. The stereotypic class is typified by monotonously repetitive, frequently rhythmic acts, e.g., head-banging, and is most often associated with developmental disability. Finally, the superficial-moderate class is characterized by episodic, repetitive behaviors, such as light self-cutting, and is most often associated with borderline personality disorder (5).

Unlike the stereotypic self-injurious behavior that is most typical of the developmentally disabled, our patient's self-mutilation is from the major class. Eighty-seven percent of major-class episodes occur in psychotics (6). We cannot exclude our patient having suffered from psychosis or "micropsychosis" induced by family stressors, and his conscious motive of

Jefferson Journal of Psychiatry, Volume 21, Number 1

(C) 2007 by the authors

On the Web: jdc.jefferson.edu/jeffjpsychiatry

ISSN 1935-0783 
injuring his penis to injure his father may be explained as delusional, but we have no other evidence that the patient was psychotic at the time he acted.

A classic psychological model, one in which self-mutilation is employed as a primitive coping mechanism to relieve anxiety, may apply: the patient was disturbed by termination of his relationship with his father and destabilization of his home environment. Yet his surprise when he experienced pain argues against this model in his case, or perhaps suggests that his was a failed experiment in using self-injury to relieve psychological distress. Self-mutilation has been strongly linked to having been abused as a child and to dissociative symptoms $(7,8)$. Our patient's seeming inability to recall much that surrounded his self-mutilation could, possibly, represent dissociative amnesia.

Children with FAS are often raised in chaotic social environments (9), which, along with their cognitive deficits, cause poor psychological and social development. Hence maladaptive behaviors and primitive defenses are maintained well into adulthood. The unusual feature of the case we report here is that of major-class self-mutilation in the absence of definite psychosis.

\section{SOURCE INFORMATION}

From the Department of Psychiatry and Behavioral Sciences, University of California, Davis, Sacramento CA 95817. Direct inquiries to James A. Bourgeois, OD, MD: james.bourgeois@ucdmc.ucdavis.edu.

\section{REFERENCES}

1. Abel EL, Sokol RJ. Fetal alcohol syndrome is now leading cause of mental retardation. Lancet $1986 ; 2: 1222$

2. O’Malley KD, Nanson J. Clinical implications of a link between fetal alcohol spectrum disorder and attention-deficit hyperactivity disorder. Can J Psychiat 2002; 47:349-354

3. Burd L, Klug MG, Martsolf JT, Kerbeshian J. Fetal alcohol syndrome: neuropsychiatric phenomics. Neurotoxicol Teratol 2003; 25:697-705

4. Lewis M H, Gluck J P, Bodfish J W, Beauchamp A J, Mailman R B (1996). Neurobiological basis of stereotyped movement disorder. In Stereotyped Movements: Brain and Behavior Relationships, ed Sprague R L, Newell K M, pp 37-68. Washington, DC: American Psychological Association

5. Favazza AR. The coming of age of self-mutilation. J Nerv Ment Dis 1998; 186:259268

Jefferson Journal of Psychiatry, Volume 21, Number 1

(C) 2007 by the authors

On the Web: jdc.jefferson.edu/jeffjpsychiatry

ISSN 1935-0783 
6. Greilsheimer H, Groves JE. Male genital self-mutilation. Arch Gen Psychiat 1979; 36:441-446

7. Nijman HL, Dautzenberg M, Merckelbach HLGJ, Jung P, Wessel I, Camp J. Selfmutilating behavior of psychiatric inpatients. Eur Psychiatr 1999; 17:1-7

8. Winchel RM, Stanley M. Self-injurious behavior: a review of the behavior and biology of self-mutilation. Am J Psychiatry 1991; 148:306-317

9. Streissguth AP, Aase JM, Clarren SK, Randels SP, LaDue RA, Smith DF. Fetal alcohol syndrome in adolescents and adults. JAMA 1991; 265: 1961-1967 


\section{FIGURE}

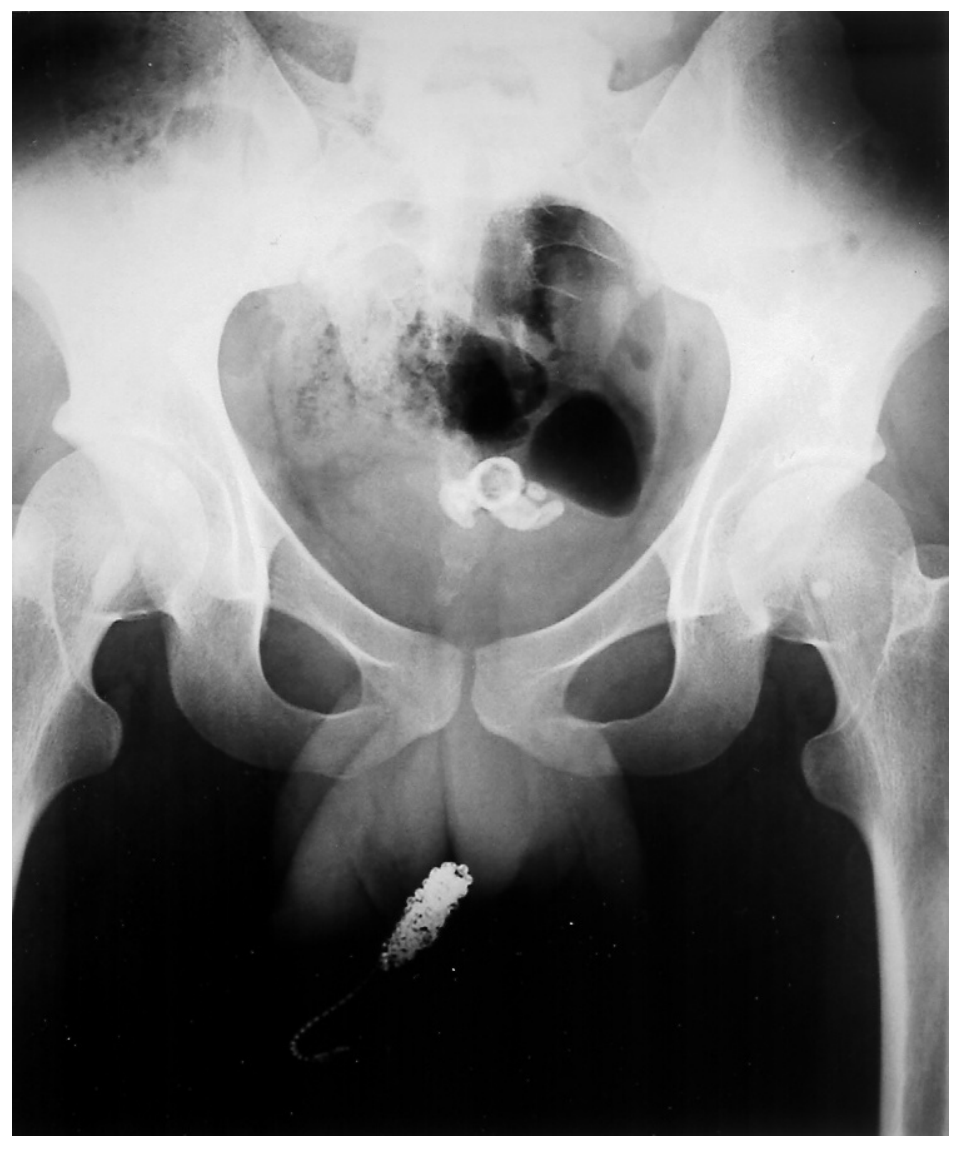

Figure 1. Abdominal film shows a coiled metal chain $(50 \mathrm{~cm} \mathrm{X} 0.5 \mathrm{~cm})$

lodged within the urethra, and a separate mass, which was later identified as a toy frog $(1.5 \mathrm{~cm}$ X $2.0 \mathrm{~cm} \mathrm{X} 2.5 \mathrm{~cm})$, within the bladder. 